\title{
The Intercultural Aspect in Business: An Approach to Communicative Misunderstandings in the Professional Interactions in Business in Morocco
}

\author{
Amina SAOUSSANY \\ Ibn Zohr University, National School of Business and Management of Agadir/Morocco, Morocco
}

\begin{abstract}
What are the main difficulties in intercultural communication encountered by the students of the National School of Business and Management of Agadir (ENCGA)/Morocco during their interaction with French native managers in Moroccan companies? This is the main question we will try to answer in the present article. From two different methods: the participant observation and sound recording of communicative interactions, the study has addressed the fundamental issues related to the problems of communication with the other in an intercultural professional environment. The conclusions drawn from the analysis of the data suggest some pedagogical readjustments to improve the teaching of intercultural communication in the ENCGA.
\end{abstract}

Keywords: intercultural communication, ENCGA, misunderstanding, interaction

\section{Introduction}

The idea that we should manage the relations between the natives and the non-natives raises a remarkable interest and gives the feeling of well-being to the interlocutors. Working to unite the differences and to look into the gaps of the world while searching for the things that can bring them together provides an immense pleasure to researchers in intercultural communication.

There are many students of ours who face in their experience of internship the challenge of the exchange with the other. They are excited to work on a human project, which is to organize the meeting and to enter into communication with this other that fascinates them. The intercultural aspect in business is a seductive project. It raises the question of the relationship between cultures in terms of cultural distance. The implicit assumption is that the greater the difference, the higher is the intensity of the conflict and the more necessary is the calls to specialists to lift the ambiguities, clear the misunderstandings, and reduce tensions.

The issue of our work is inspired by the work on the ethnography of communication and the interactional approach. In fact, communication is a fundamental phenomenon of culture where the social relationships and the exchange between people of different cultures are subject to interruptions and misunderstandings which emanate from the cultural differences between the communication partners (Camilleri \& Emerique, 1989). On the other hand, the interactional analysis presents the tools and concepts for studying verbal interactions and apprehending the communicative difficulties in a professional environment.

Amina SAOUSSANY, professor-researcher, authorized professor, Ph.D., Ibn Zohr University, National School of Business and Management of Agadir/Morocco, Morocco. 
To determine the nature of misunderstandings and their explanatory sources, we issue two hypotheses: The first relates to the lack of knowledge of non-native interns of interactional standards in the French language. The second is relative to the hierarchical relationships and the type of management applied-participative or authoritarian - that would be the basis of the misunderstandings in the interactions between the partners of the exchange.

\section{Methodology of Data Collection}

\section{Selection of the Public of Investigation}

The public which is the focus of our research consists of students of the fourth year of the ENCGA (2014-2015). These Moroccan students, who came from different regions of the country, have to spend five years at the ENCGA in the framework of their training in business and/or management. They are intended to work in business as business agents, managers, responsible for the audit, responsible for human resources, advertising, heads of prospecting and marketing...

On their admission to the ENCGA in September 2010, students were 230. During their passage in the fourth year, they were 210. These are called at the end of their university curriculum, to carry out a month internship in business and to conduct a field research in the services where they are affected in order to deal with specific problems in relation to their areas of specialty. The objective is to produce a project at the end of the study which will be defended before a jury composed of professionals and academics.

The companies, places of our investigations, are 24 in number. They operate in different sectors of activity (food processing, industry, tourism...) and cover all Moroccan territory. To maximize the possibility of updating and identification of the situations of intercultural misunderstanding between the students and the French managers, we thought it was useful to take into consideration all the companies at the start before deciding on those that we would retain in our research.

\section{The Professional Profile of French Managers}

In Moroccan companies, for historical reasons or for those related to privatization or to direct investment, Moroccan executives work in collaboration with their foreign counterparts. The French executives are the majority in comparison to the Italians and the Spanish. These hold different positions within their businesses: chief executives, business owners, responsible for marketing and sales, financial directors, managers of subsidiaries of French companies in Morocco, managers...

\section{The Collection of Data}

The participant observation. With a view to examine more closely the real situations of language interactions and to observe how the exchanges between the French speakers and Moroccan trainees are, we have conducted some field observations. My status as coordinator of the commission of internship has allowed me to easily integrate the services of assignment of Moroccan student-trainees and see the way in which these students manage their communications with their French partners.

Nevertheless, the participant observation was not systematic in our case. In fact, it is difficult for us to be present in all places and at all times given the remoteness and the significant number of the host companies. The data of the participant observation is therefore likely to be approximate and unreliable, but their importance for our work is significant in view of the fact that they have allowed us to account for the non-verbal elements 
of the communication ${ }^{1}$ that the sound recording could not raise.

The sound recordings. We have proceeded to the registration of the verbal interactions between the students and the French managers in the services, places of the internships. To ensure the reliability of the information, we have asked the supervisors of the internship in the companies to save exchanges through tape recorders put under the offices within the services.

In parallel to these two methods, we have asked our students to take notes of the difficulties of communication that they would encounter during their internships.

The sound recordings have not all been the object of transcripts given their large number. We have, in fact, only accepted the interactions with signs of misunderstandings. The criteria of selection determined after listening to the audio tapes are as follows:

(1) Rupture of interaction between the partners of the exchange as a sign of failure of communication;

(2) Prolonged silences in the interaction;

(3) Manifestation of disagreement between the two parts of interaction.

Each transcribed interaction will be the subject of an analysis to see the misunderstanding(s) which occurred, their verbal peculiarities (language...), and non-verbal charracteristics (kinesique, proxemics...). Each misunderstanding ${ }^{2}$ shall be presented with the help of examples from the data then studied. The approach shall explain the nature of the misunderstanding contained in the interaction, its types as well as the indices of the Hierarchical reports expressed through the minutes and the non-verbal acts.

\section{Analysis of the Listed Misunderstandings}

\section{The Strategies and Sequences of Starting Conversations}

The opening and closing are moments particularly sensitive in the interaction. They often involve threats to the faces of the actors of communication. The hard core of the sequence of opening is making contact. In the context of Morocco, the communicative interactions are usually opened by a ritual of a socially marked greeting: /Salamoualaykoum/ (that peace be on you). This ritual means that the greeter reassures his interlocutor and sends a message of peace.

In business, the procedure for taking contact, beyond the cultural dimension, presents a special feature related to the hierarchical relationships which impose other standards in the strategies of starting conversations: The rule is that the higher addresses the subordinate. The initiative of taking the initiative is his responsibility.

The following example illustrates a misunderstanding in the strategies of starting conversations:

Place of interaction: commercial service in a bank

Speakers: Moroccan trainee (t) and French customer (c)

Situation: The trainee, having finished dealing with a customer who has just left the office, is busy classifying a folder. During this time, a French client, without manifesting his presence, is waiting at the door of the office. Without raising his eyes, the trainee expects that the customer addresses him and formulates his

\footnotetext{
${ }^{1}$ In an intercultural meeting, the role of non-verbal signs becomes more significant because the acquisition of the language of communication for the partners is not enough by itself (Abdellah-Pretceille \& Porcher, 1996, p. 82).

2 The misunderstanding is a concept used in the field of intercultural communication, to designate a situation in which the communication undergoes a failure. It is defined by Orgogozo (1988, pp. 75-76) as "a non-intercultural isomorphism of cognitive grids implied, underlying the communication". The misunderstanding, from this point of view, would express "the difference between sense and meaning (...). It is this that prevents the meaning given to things is the same for the two interlocutors" (Fenoglio, 1995 cited by Vion, 2000, p. 189).
} 
request. The French, seeing the trainee eyes down, expects that the latter asks him about the purpose of his visit.

S: (eyes down, keeps silent and waits)

F: (keeps silence and waits)

S: (after waiting for a moment, he lifts the head) Hello, can I help you?

F: Hello! Yes...it is about the transfer that I made to your bank (handing the papers).

On the intercultural plan, this situation of communication includes a misunderstanding. For the trainee, to engage the conversation is the responsibility of the customer because he is the applicant for the service. In addition, the latter who is in a standing position has just entered the office. Complying with these standards, the trainee does not understand the expectation and hesitation of the French customer.

On the other side, the French who usually "raises the eyes when a person comes within his field of vision" (Beal, 1993, p. 82), and that "it would be rude not to do so" (1993, p. 82), hesitates and does not understand the attitude of his interlocutor. The difference in the way of making contact between two people from the two different cultures is therefore the generator of misunderstandings and communication breakdowns.

Professionally, this misunderstanding would be due to the absence of a business culture for the Moroccan trainee. The interactive framework of the exchange is of an institutional nature. The trainee is in a high position (service provider) while the customer is in a low position (service applicant). Not having embodied his role of responsible within the bank (applied internship), the student who played the role of a trainee, has responded in accordance with his cultural standards as to starting a conversation. In this situation of communication, the mutual incomprehension of the reactions of the two partners in the exchange, finds its explanation, beyond the professional dimension, namely in the cultural variation of the strategies of building contact used by the two Moroccan and French interlocutors.

\section{The Ritual of Greeting}

The greeting constitutes an act of speech which expresses the friendship and the tribute that we owe to the interlocutor. The salutations are various from one situation to another and from one culture to another. Traditional societies generally use a succession of forms of greeting that non-native speakers would find unnecessary. The following situation is an example of that:

Interlocutors: trainee $(\mathrm{t})$ and French executive (e)

Location: Financial Service

Time: 9 am

Situation: French manager, after an absence of a few days, resumes work.

T: (Seeing the French executive coming) Hello! Mr Pascal...

E: Hello Ahmed!

T: How are you?

E: Fine thanks. And you?

$\mathrm{T}$ : And how is the small family?

E: Well, thank you and y....

$\mathrm{T}$ : And the children? 
F: (silence) So, is your Work at the accounting service completed?

T: (extended silence) Not yet sir.

The exchange would have been developed on the new theme (work of accounting) initiated by the French manager. In fact, surprised by the evasive response of the student and by his long silence, the French executive has not pursued the interaction. On his side, not having received a response on the health of the interlocutor, the Moroccan trainee perceived the change of theme as a sign of the desire to terminate the discussion.

In this interaction, the misunderstanding, source of rupture of the exchange, has created a dissatisfaction shared by the two interlocutors. Indeed, the French felt embarrassed to give in detail the news about himself, his family, his children, etc. From his side, the Moroccan trainee has manifested a misunderstanding by the prolonged silence of the French because he has not received a response to the question: And the children? According to him, changing the theme of discussion in the interaction reflects the desire to establish a distant relationship with his interlocutor.

The rituals of greeting in the Moroccan society fall within the social norms. They are rich in their informational content. They are repeated and are valued socially and culturally. The questions on the family, children, health, work, etc., are the elements of a ritual of greeting developed at each meeting. They are also a means to avoid the silence in social meetings because meeting someone without saying anything is a threat to his face. In addition, the reciprocal nature of greetings is valued; any absence of reciprocity may be an act threatening the face of the interlocutor.

The cultural difference in the rituals of greeting is at the origin of the misunderstanding marked in this example.

\section{The Management of Space: the Interpersonal Distance}

The concept of personal territory refers to the way to manage the space and limit the space borders vis-a-vis the other. Goffman (1974, p. 44) defined the personal space as "the portion of space that surrounds an individual and where any penetration is felt by him as an encroachment which causes a manifestation of displeasure and sometimes withdrawal".

Edward Hall (1971, p. 170) designed the space as a means of communication. He divided the interpersonal distance in four categories:

(1) The intimate distance ( 0 to $40 \mathrm{~cm})$;

(2) The personal distance (45 to $125 \mathrm{~cm}$ );

(3) The social distance (from 120 to $360 \mathrm{~cm}$ );

(4) The public distance (360 $\mathrm{cm}$ and more).

The greater the degree of intimacy is reduced, the bigger the interpersonal distance gets. Within companies, the students have expressed difficulties in integrating the work teams. Indeed, the staff considers the space-Service as a proper territory for the employees of the company. The relationship with the outsider (the trainee) comes under the sign of "distance".

On the other hand, the interpersonal distance is a sign of a hierarchical relationship and is culturally marked. For a Moroccan, this distance increases as the interlocutor is a foreigner (non-native speaker) or has a higher status (placed at the top of the hierarchy).

The example below elicits the misunderstandings in communication that the interpersonal distance could generate: 
Place: Computer Service

Speakers: Executive (French) and computing trainee (Moroccan).

Situation: The Moroccan trainee and the head of the IT department discussed the computer security. The two are in the office of the executive.

E: (Sitting in his office) I think/ for this history of computer security/We must think seriously.../

$\mathrm{T}$ : Yes... I think that this is a current subject which concerns... all companies/

E: I believe that the companies that operate in a network/ are more exposed to this problem than others/

T: I think that Moroccan firms do not have... will not have the same difficulties that/those of industrialized countries and.../

E: Yes definitely/ It is clear/ THERE/ everything is computerized... the public services as/but the phenomenon of computer security... it concerns all countries uh/to different degrees.../

$\mathrm{T}$ : It is/better this way/yes it is a question of ...

E: Are you used to...

T: To what

E: /To leaving your office to sit before/here... opposite...

T: Ah! No No/I wanted to ask... a question...

E: (Silence) Ah! Yes

T: In fact, would you mind if/we got closer...

E: A closer distance... YES

$\mathrm{T}: \mathrm{Ah} ! \mathrm{I}$ see/... in fact/ I understand why...

In this interaction, the development of the topic is done in a progressive manner until the exchange: "It is/better this way/yes it is a question of...". We are witnessing from this exchange a change of topic of discussion. The question "in fact would you mind if/we got closer..." and the response "a closer distance...YES" explains what generates the thematic breakdown. It is the relational distance between the two interlocutors. Here, the lack of understanding in the exchange has focused on the design of the proximity. To move from his office to be closer to his French interlocutor who is embarrassed by this movement of space means for the trainee a willingness to invest in the discussion. The cultural differences in the management of the space are at the origin of the misunderstanding in this example. The proxemics is perceived differently in the exchange of the two speakers.

\section{The Body of the Interaction}

The alternation of turn taking. C. Kerbrat-Orecchioni (1998, p. 2) distinguished companies with a strong hierarchical culture in which speech taking is governed by a normative order explained by the company status of the interlocutor from the companies with a low hierarchical culture ${ }^{3}$.

The following example shows power relationships; within the company:

Place: Service of Accounting

Interlocutors: Trainee (Moroccan) and Accounting manager (French)

\footnotetext{
${ }^{3}$ In this same perspective, Hofstede (1987, p. 45) spoke of two types of companies from the point of view of managerial capabilities. He made a distinction between a company of high hierarchical distance and a corporation of low hierarchical distance.
} 
T: Hello Sir! Could you please hand me the financial documents of the previous years to see the evolution of "Fantasia"?

M: Listen, the boss does not accept that we touch these documents without his authorization. There are many people who seek only to create problems...

T: Sir, I am only a trainee and I would just like to understand the evolution of the company...

M: I know, but I risk my position if I do that.

In this interaction, the misunderstanding is implicit and is caused by a blunt refusal of a clearly stated request. The justification that the chief of the accounting service formulates is not well founded in the eyes of the Trainee; it emanates from the desire of the chief to mark a hierarchical distance. The intern is in a low situation and the French executive is in a high situation. The hierarchy of the two interlocutors is the generator of this implicit misunderstanding.

Overlaps and interruptions. Gerard-Naff $\left(1987\right.$, p. 44) cited by Candea $(2000, \text { p. } 56)^{4}$ defined the overlap as:

A simultaneity of short duration, generally on the last syllable of the speech of the current speaker at the precise moment when this latter comes to a possible transition... it is an error in the setting of the alternation but which is perceived as a violation. (Gerard-Naff, 1987, p. 44; Candea, 2000, p. 56)

In situations of intercultural communication, overlaps are at the origin of misunderstandings. The example that follows explains this:

Place: Production Service

Interlocutors: French executive (E) and Moroccan trainee (T)

(L1) T: You know that/ that there is today a/a debate on the effectiveness of the (L2) application of the system of the continuous schedule in the Moroccan administration.

(L3) E: yes/I heard about it/me/I think that it is a good thing.

(L5) T: I (pause 20s)

(L6) E: Because you see.../ there is economy of a number of things...in the first place for our company the staff has the habit to go home for lunch/....

(L9) T: The issue is/to know/if this experience has/has the//

(L10) E: The success/

(L11) T: Because the/the different institutions are not/not equipped/

(L12) E: Which means/which means, it is part of the responsibilities of the state. I believe that well/well there is no reason why we shouldn't follow the decision of the continuous schedule by the means of application

(L15) T: Ah/Yes: : : But... the/the (silence)

(L16) E: Any way, it is good to/to apply the continuous schedule... You see last year our staff appreciated the system.

(L17) T: (Silence) But the/the...

(L18) E: That is to say every experience may have some/some failure.

\footnotetext{
${ }^{4}$ Candea, M. (2000). Contribution to the study of silent pauses and "hesitation" phenomena in spontaneous oral French, Ph.D. thesis, Sorbonne Nouvelle University, Paris 3.
} 
(L19) T: But this/ it is/this but yes it is sure (silence)

(L20) E: You don't seem convinced

(L21) T: No; I mean/ you are going a bit fast for me.

In this interaction, the trainee manifests difficulties to take a position in the exchange. Several overlaps and interruptions are highlighted. In the second round of speech, the trainee, wishing to express his opinion (L5), is short-circuited by his French interlocutor. The response of the Trainee which starts by an "I" and is followed by a pause of 20 seconds is broken by the intervention of the French. The "I" of the trainee and the "because" of the French are actually, pronounced at the same time. Similarly, in L16, the French executive irritated by the silence of the trainee, has interrupted his interlocutor to express his point of view (any way it is good of...).

The opening of this interaction is marked by the presence of intra-response pauses ( 3 short pauses) and the presence of an interruption made by the French interlocutor L10. This latter has completed the response of the trainee by the word "... of success". Again, we are witnessing an overlap followed by an interruption on the part of the French. In fact, the latter by the use of the expression "that is to say" two times, pronounced at the same time with the word "equipped" of the previous response, has obliged his Moroccan interlocutor to abandon his turn before the end. Such a rupture causes, within the trainee, in the following response, an attitude of withdrawal (ah! Yes: But HM (silence)...). The regulator "Yes" in the syllable is elongated, followed by the "but", normally marker of the introduction of a new position or of an objection, has not led to convey a developed turn taking. The result is the silence linked to a break, but it is the reflection of a lack of understanding of the various overlaps produced by the French interlocutor.

This example of interaction presents overlaps and interruptions that have led to a communicative misunderstanding. This can be explained by the differences between the Moroccan and French in the way of managing the interactions. In fact, in French conversations, the interruptions and the overlaps are tolerated. They are not barriers to the success of the exchange, but elements that reinforce interaction. Kerbrat-Orecchioni (1998) said in the sense that:

"For a French, interruptions, if they are not too frequent (...) allow to accelerate the tempo of conversations; they give them a lively character and produce an effect of heat, spontaneity and active participation, generally appreciated in our society" (p. 28).

Such a cultural fact proper to the French society is interpreted, in an intercultural communication, as a willingness to monopolize speech.

The overlaps and interruptions have therefore an intercultural character and are generators of misunderstandings. They could also have their origin in the non-mastery of the French language by the Moroccan trainees. Indeed, being non-native speakers of the French language, they sometimes have difficulty finding the words; which could cause interruptions in the interaction.

The expression of request. The request is an act which varies in its realization depending on cultures and languages. Many studies have been devoted to the forms of request. As an example, we include the work of Searle (1985) for the function, Evrin-Tripp (1964) on categories and types, and Blum-Kulka, House, and Kasper (1989) for the main structures of the request and the different strategies of the expression.

The following example illustrates the case of the request:

Place: financial service of an import/export business. 
T: Hello!/Mr. That is/ I am trainee and I work on/on an operational audit draft of purchases and sales.../ I need information on the financial balance sheet of the previous accounting year. Are you able of giving me this information if it pleases you I.

F: Well.../ (silence) If I am able of I...

Maybe/ But.../ What kind of information I?

$\mathrm{T}$ : (Silence) Concerning the financial balance sheet of last year...।

F: To tell you the truth/I do not know if this kind of information are useful for an audit work... because they are confidential... you know well that there is a strong competition...

$\mathrm{T}$ : Yes/SO/IS/IT is always such a/question of confidentiality of information...।

F: Usually/it is the whole problem of trainees which/it is a delicate question... yes... delicate

T: Do you see/ Now, it is a little difficult to/for for...

F: To have the information/ Uh especially the most current/finally/ it is possible to give information which/ are Not/ of accounting nature...

In the presented interaction, the request is expressed by the question: Are you able of giving me information, please? This phrase is interpreted by the French interlocutor as a doubt in his competence, which has led to a communicative misunderstanding which justifies the reaction of the trainee in the interaction.

The element on which the misunderstanding "be able" is in the Arabic language (translation "bimaqdourika") one of the ways to express the request. The transfer of the expression of request from Arabic to French has led to a misunderstanding for the French executive which could be explained by the lack of awareness of the Moroccan trainee of the cultural aspects related to the expression of request in the foreign language.

The expression of compliments. The compliment is a positive evaluative assertion. It is also a flattering expression which is directed to a person to congratulate him/her. The expression of compliment is governed by culture and its formulation in an intercultural context may be the subject of misunderstandings. The following interaction is explicit in this sense:

Situation: After completing the balance sheet of accounting operations the internship supervisor in the company, the French executive (f) asked the trainee ( $t$ ) to give him the complete file.

F: (Two days after receipt of the file) Your work is good. You have done a good performance. We feel a great internal coherence. Bravo

T: Sir, this is not a big thing; I have worked hard on it, but...

F: This is not true! Of course nothing is perfect but by and large it is not bad. Don't you think so?

T: (Silence) Yes......Mr.

The above example presents another type of misunderstanding. It is relative to the interpretation that the two interlocutors of the act compliment have made. In fact, in the face of the compliment of the French executive (congratulations for the work done), the student replied: "This is not a big thing". The latter has not taken into consideration the compliment of the French executive. This answer seems to surprise the compliment maker who expected to be thanked.

The reaction of the trainee in the face of compliment could be perceived as a lack of politeness by the French interlocutor while it is a sign of modesty which is valued socially by the Moroccan trainee. The 
misunderstanding in this interaction is due to lack of knowledge by the partners of the cultural values related to the expression of compliment in the culture of the other.

\section{The Didactic Implications in the Teaching-Learning of Communication}

The different communicative misunderstandings identified in our study are due to the ignorance of the Moroccan students of interactional standards conveyed by the French language as culturally and conventionally coded signs. They also find their explanation in the hierarchical relationships which are not equal among the partners in the exchange and in the inequalities in the mastery of the French language between native and non-native speakers.

To succeed in the communication with the speaker of French in the workplace, the teaching-learning standards of interactional French as a foreign language must be integrated in the educational program of communication provided to the ENCGA students. The ethnography ${ }^{5}$ of communication "is of considerable practical value in areas such as the teaching of second and foreign languages, as well as in all the sectors concerned with the intercultural communication" (of Salins, 1992, p. 15). It is used to develop the communicative competence of students in their learning to use the language in function within the social context of the exchange and the interlocutors. The objective is to enable them to acquire a communicative and interactional skills to facilitate their communication with native speakers (French) in the enterprises where they will work as future executives.

For pedagogical recommendations and in order to develop the communicative competence of students in the multilingual context, we offer activities such as role play and business simulation in which students update under playful actions, specific social roles, and specific statutes. The objective is to incorporate a set of conventional sociolinguistic rules and allow students to develop skills of communication either with a native or a non-native.

French films dealing with managerial issues or specific themes tackling corporate French issues (audit, finance, trade, purchase/sale...) would be important in this direction. They would allow the Moroccan students to know the standards of interaction in French and to understand the socio-cultural context of the other. The observation of the gestures, proxemics... would also be important. While drawing the comparison with Moroccan corporate films, they would understand the differences in the modalities of operation of the interactions.

The audio recordings of our survey could also be studied in class. The objective is to bring the students to identify misconceptions and misunderstandings and to identify their sources and their origins. The analysis of the verbal and non-verbal actions of the two interlocutors and the apprehension of the modes of operation of French-Moroccan intercultural interactions (Strategies for starting conversations, the greetings, the aspects taking into the conduct of the interaction, the expression of requests and compliments, the operation of turn taking, the management of the look...) could also be considered to understand the issues of intercultural communication and learn how to communicate effectively with the other which amazes us and that we want to know.

\footnotetext{
${ }^{5}$ Incorporated in the years 60, the Ethnography of the communication is a current form of research from linguistics and anthropology (Abdellah-Preitcelle \& Porcher, 1999). Its founders Hymes (1984) and Gumperz (1989) define it as a discipline "which approach the language or as abstract form nor as correlation of a community, but as located, anchored in the flow and the model of events of communication. (...) The goal must be to keep in view the Multiple hierarchy of relations between message and context" (of Salins, 1992, p. 112).
} 


\section{Conclusion}

The analysis of professional interactions in business is the responsibility of the Ethnography of communication. This field of study insists on the dynamic character of verbal interactions and takes into account the use of situational language. It rejects any separation between the social, the cultural and the linguistic aspects, and concludes the role of the socio-cultural code in the study of communicative difficulties of the interlocutors in a situation of intercultural exchange.

The Ethnography of communication gives priority to the notion of interaction. Here comes the role the interactional approach which is interested in the analysis of natural and authentic conversations taking into consideration the verbal and non-verbal channels of communication. The analysis of the professional interactions selected reveals that the misunderstandings identified are in largely due to the lack of knowledge of the Moroccan students of interactional standards of the French language and the cultural aspects which underlie them. The nature of the hierarchical relationships within the Moroccan company would also explain these misunderstandings.

Beyond the cultural and hierarchical differences, the communicative difficulties of Moroccan trainees with the native French are explained by the Linguistic asymmetry between the two interlocutors. The non-mastery of the French language by the non-native speaker puts him/her in a situation of linguistic inferiority, which creates failures and blockages in the professional interactions.

The conclusions of our work have resulted in pedagogical proposals for improving the teaching of the communication in the French as a Foreign Language to the ENCGA students. The interactional standards of the French language should be integrated in the training provided to students hand in hand with language rules. The objective is to enable the students to communicate effectively in intercultural professional contexts with non-native speakers without the risk of misunderstandings or ruptures of communication.

\section{References}

Abdellah-Pretceille, M., \& PORCHER, L. (1996). Education et communication interculturelle (Intercultural education and commmunication). Paris: University Press of France.

Abdellah-Pretceille, M., \& PORCHER, L. (1999). Diagonales de la communication interculturelle (Diagonals of intercultural communication). Paris: Anthropos. Diffusion Economica.

Beal, J. C. (1993). Les stratégies conversationnelles en Français et en Anglais. Conventions ou reflets de divergences culturelles profondes. (Conversation strategies in French and English. Conventions and reflects of deep cultural divergences). French in the World, 98, 79-106.

Blum-Kulka, S., House, J., \& Kasper, G. (1989). Cross-cultural pragmatics: Requests and apologies. Norwood, NJ: Alblex Publishing Corporation.

Camilleri, C., \& Emerique, C. (1989). Chocs des cultures: Concepts et enjeux pratiques (Culture shock: Concepts and practical risks). Paris: Harmattan.

Candea, M. (2000). Contribution to the study of silent pauses and "hesitation" phenomena in spontaneous oral French (Ph.D. thesis, Paris, Sorbonne Nouvelle University, Paris 3).

De Salins, G. D. (1992). Une introduction à l'ethnographie de la communication. (An introduction to the ethnography of communication). Paris: Didier.

Evrin-Tripp, S. (1964). Language and thematic apperception test content in bilinguals. Journal of Abnormal and Social Psychology, 68, 500-507.

Goffman, E. (1974). Les rites d'interaction (The usage of interaction). Paris: Midnight Edition.

Gumperz, J. (1989). Engager la conversation, introduction à la sociolinguistique interactionnelle (Starting a conversation, an introduction interactional sociolinguistics). Paris.

Hall, E. (1971). La dimension cachée (The hidden dimension). Paris: Threshold Edition. 
Hofstede, G. (1987). Les différences culturelles dans le management. Comment chaque pays gère-t-il ses hommes? (Cultural differences in management. How each country manages its means?). Paris: Organizational Éditions.

Hymes, D. (1984). Vers la compétence de communication (Towards communication competence). Paris: Hatier.

Kerbrat-Orecchioni, C. (1991). L'acte de question et l'acte d'assertion: opposition discrète ou continuum? (Question act and assertion act: Discrete opposition or continuum?). Paris: Nathan University.

Kerbrat-Orecchioni, C. (1998). Les interactions verbales. Approche interactionnelle et structure des conversations (Verbal interactions: An interactional approach and a structure of conversations). Paris: Armand-Colin.

Orgogozo, I. (1988). Les paradoxes de la communication (The paradoxes of communication). Paris: Organizational Editions.

Searle, J., \& Vanderveken, D. (1985). Foundations of illocutionary logic. Cambridge, England: Cambridge University.

Vion, R. (2000). La communication verbale: analyse des interactions. (Verbal communication: Interaction analysis). Paris: Hachette Université. 